\title{
On the trail of an auditory rabbit
}

\author{
WILLARD R. THURLOW and ROBERT E. ONESON \\ University of Wisconsin, Madison, Wisconsin
}

\begin{abstract}
The auditory "rabbit," or saltation, effect has previously been described as arising when a small number of auditory pulses (e.g., three) are presented at each of three positions in space, in rapid succession: $\mathrm{P}_{1}, \mathrm{P}_{1}, \mathrm{P}_{1}, \mathrm{P}_{2}, \mathrm{P}_{2}, \mathrm{P}_{2}, \mathrm{P}_{3}, \mathrm{P}_{3}, \mathrm{P}_{3}$. The pulses appear to be spread evenly in space, occupying positions not only at their physical places of origin, but also between those places. The present experiments measured direction and amount of spatial displacement effects quantitatively: Localization was measured for the next to last pulse in a sequence of three or four pulses presented rapidly at several spatial locations. Direction of displacement of this pulse was found to depend on its physical location relative to other pulses in the series. Magnitude of the displacement depended on the number of pulses in the series, and on the spatial location of the last pulse in the series relative to that of other pulses.
\end{abstract}

Geldard and Sherrick (1972) described a cutaneous "rabbit" effect (more formally described as "sensory saltation"'). Geldard (1975, p. 28) provided an illustration, as follows: "Three identical contactors are placed about 4 inches apart on the forearm. Each is capable of delivering a sequence of sharp taps, being energized by square waves of only a few milliseconds duration. Now let the three contactors be put into operation sequentially, each in turn receiving five rapid pulses and with no pause in passing from one vibrator to the next. In the right range of repetition rates-and this can be anything from 5 to 50 pulses per second, optimally about 20 -instead of feeling three well-spaced bursts located under the contactors, the 15 taps appear to distribute themselves uniformly from the region of the first contactor to that of the third. There is a slow, sweeping movement punctuated by taps. The impression is that of a tiny rabbit hopping up the arm."

Subsequently, they found that a displacement effect could be obtained with a three-pulse sequence, the effect obtained being called the "reduced rabbit." $P_{1}$ and $P_{2}$ occur at the same cutaneous position, whereas $\mathrm{P}_{3}$ occurs at a second cutaneous position. $P_{1}$ occurs $800 \mathrm{msec}$ before $P_{2}$. As the interval between $P_{2}$ and $P_{3}$ is reduced to about $150 \mathrm{msec}$, the position of $P_{2}$ is perceived to move closer to that of $P_{3}$, until finally its position coincides with that of $\mathrm{P}_{3}$.

Bremer, Pittenger, Warren, and Jenkins (1977) looked for an auditory analogue to the cutaneous rabbit and found one. They used three loudspeakers, one directly in front of the subject and the other two at equal angles on either side $\left(23^{\circ}\right)$. Three clicks came from each loudspeaker, with intervals between clicks of $10-250 \mathrm{msec}$. When the interval between clicks was short (less than $100 \mathrm{msec}$ ) and regular, the clicks were perceived to be spread out evenly between the positions of the actual sources as well as at

The authors' mailing address is: Department of Psychology, University of Wisconsin, Madison, WI 53706. these positions. Geldard (1975) reported similar findings. Sherrick (described in Geldard, 1975, p. 86) reported results for a "reduced auditory rabbit" very similar to those found for a cutaneous "reduced rabbit." He found very large displacements (up to $60^{\circ}$ ) and obtained displacements for time intervals up to about $300 \mathrm{msec}$. These results do not appear to agree with the other results, which show relatively small displacements, and then only when pulse time separations are less than about $100 \mathrm{msec}$.

Our Experiment 1 was designed to measure displacement effects for the next to last pulse in a sequence of three or four pulses. Measurement of localization of a particular pulse has an advantage over simply asking subjects to judge "evenness" of perceived spatial locations of pulses: One can determine in which direction a given pulse shifts, as well as the precise amount of displacement due to presentation of the pulse in a sequence. We wished to find whether displacements in both directions could be obtained, and whether the effects would be stronger with a four-pulse sequence than with a three-pulse sequence. We chose pulse separations $(50,100,150 \mathrm{msec})$ that would be short enough to produce displacement effects, but that would not be short enough to involve what are probably different kinds of localization interaction effects. For pulse separations shorter than about $50 \mathrm{msec}$, localization interaction effects between pulse pairs have been observed such that the perceived localization of one pulse is affected by the other or such that the localization of one pulse may be suppressed by another (Blauert, 1983; Thurlow, Marten, \& Bhatt, 1965).

\section{EXPERIMENT 1}

\section{Method}

Subjects. Twelve undergraduate students served as voluntary participants.

Apparatus. Pulses were generated by leading a .1-msec electrical pulse from a Tektronix pulse generator (Type 161) through a transformer (UTC-33) to a loudspeaker (Realistic, 2.5-in. diameter). The pulses produced were at a sensation level of approximately $40 \mathrm{~dB}$. Loudspeakers 
were $3 \mathrm{ft}$ from the center of the subject's head. They were mounted on a semicircular frame, in a room lined with fiberglass wedges. Timing of the sequence of pulses was obtained by use of a Tektronix waveform generator (Type 162).

Design and Procedure. The subjects were shown how to indicate where they heard a sound, by pointing a flashlight toward a scale marked off in degrees, fastened to the semicircular frame under the loudspeakers. The flashlight (Luxitron 40) was adjusted to give a small spot of light on the scale. The subjects were instructed to keep their heads facing straight ahead during the experiment and to rest the back of their heads against two rubber pads that were attached to the chair in which they sat.

At the beginning and end of the session, the subjects localized pulses from single speakers: Three observations were made for a pulse from the $0^{\circ}$ speaker, and three for a pulse from the $20^{\circ}$ left speaker. Five presentations of each pulse were given, at 1 -sec intervals. The subjects did not point to the perceived location of the click until after all five presentations. The subjects were blindfolded while they made localization judgments.

After the initial single-pulse localizations, the subjects were tested with the pulse-sequence conditions. Time separations of 50,100, or $150 \mathrm{msec}$ were used between successive pulses. For the three-pulse condition, $P_{1}$ occurred at $0^{\circ}$ (straight in front of the subjects) and the $\mathrm{P}_{3}$ at $20^{\circ}$ to the left. $\mathrm{P}_{2}$ (next to last) occurred at $0^{\circ}$ for half of the conditions and at $20^{\circ}$ left for the other half. The four-pulse conditions were the same except that an additional pulse occurred first in the sequence at $10^{\circ}$ right: For the four-pulse conditions, $\mathrm{P}_{1}$ occurred at $10^{\circ}$ right, $\mathrm{P}_{2}$ at $0^{\circ}$, and $\mathrm{P}_{4}$ at $20^{\circ}$ left. $\mathrm{P}_{3}$ (next to last) occurred at $0^{\circ}$ for half of the conditions and at $20^{\circ}$ left for the other half.

Five presentations of each sequence were given, 1 sequence/sec. Instructions were given to the subjects to (1) localize $P_{2}$ in the series of three-pulse stimuli and (2) localize $\mathrm{P}_{3}$ in the series of four-pulse stimuli. Three observations were obtained for each condition. Order of conditions was counterbalanced across subjects.

\section{Results}

Because of variability shown by some subjects, a median of the three observations by each subject for each condition was used for analysis of results.

In the four-pulse sequence, $\mathrm{P}_{3}$ (coming from $0^{\circ}$ ) was almost always ( 33 of 36 times) perceived as displaced to the left of its position when sounded alone. In the threepulse sequence, $\mathrm{P}_{2}$ (coming from $0^{\circ}$ ) was heard most of the time ( 26 of 36 times) displaced to the left of its position when heard alone. On the other hand, when these pulses were presented from $20^{\circ}$ left (the location of the last pulse in the series) instead of at $0^{\circ}$, they were perceived as displaced to the right of their position when sounding alone (35 of 36 times each). Simple statistical sign tests show that these displacement effects are highly significant $(p<.01)$.

An analysis of variance was performed on displacement scores for the conditions in which the next to last pulse was presented from the speaker at $0^{\circ}$. This analysis showed: (1) a significant effect of four- versus three-pulse conditions $[F(1,22)=13.90, p<.01] ;(2)$ a significant effect for subjects $[F(11,22)=2.60, p<.05]$; and (3) a significant interaction between these variables $[\mathrm{F}(11,22)$ $=3.05, \mathrm{p}<.05]$. The time separation between pulses was not found to produce a significant effect. The average displacement was $11.6^{\circ}$ to the left for the four-pulse condition and $4.6^{\circ}$ to the left for the three-pulse condition.

Another analysis of variance was performed on the displacement scores for the conditions in which the next to last pulse was presented from the speaker at $20^{\circ}$ left. This analysis showed a significant effect only for the subject variable $[F(11,22)=4.27, p<.01]$. The average displacement of the next to last pulse from its position when presented alone was $15.6^{\circ}$ to the right. (Pulses from the speaker at $20^{\circ}$ left, alone, were localized at, on the average, $29^{\circ}$ left.)

\section{EXPERIMENT 2}

Experiment 2 was carried out to find how displacements to the left, or to the right, would vary when the physical location of $\mathrm{P}_{4}$ in a sequence was systematically varied. Would location of the final pulse in the series have a marked effect on perceived location of the next to last pulse?

\section{Method}

Subjects. Twelve undergraduate students served as voluntary participants.

Design and Procedure. Experiment 2 was carried out with a fourpulse sequence and an interval of $100 \mathrm{msec}$ between pulses. $P_{1}$ was at $10^{\circ}$ right or $20^{\circ}$ right. $\mathrm{P}_{2}$ was at $0^{\circ} . \mathrm{P}_{3}$ was at $0^{\circ}$ (same location as $P_{2}$ ) or at $20^{\circ}, 40^{\circ}$, or $60^{\circ}$ left (same location as $P_{4}$ ). Order of conditions was counterbalanced across subjects.

Before and after listening to the pulse sequences, the subjects localized the position of pulses from single speaker locations at $0^{\circ}, 20^{\circ}, 40^{\circ}$, and $60^{\circ}$. As in Experiment 1, each stimulus or stimulus sequence was presented five times. When pulses from one loudspeaker were presented, the subjects pointed with the flashlight to the perceived direction of the pulses (after the fifth presentation). When a sequence of pulses was presented, the subjects were instructed to listen to the sequence of pulses, from right to left (five times), and then to point the flashlight in the direction from which they heard $\mathrm{P}_{\mathbf{3}}$. Each stimulus condition was judged three times. The subjects were blindfolded while they made localization judgments.

\section{Results}

A median of the three observations by each of the subjects for each condition was used for an analysis of results.

When $\mathrm{P}_{3}$ was presented from the speaker at $0^{\circ}$, it was almost always ( 57 of 60 times) perceived as being displaced to the left of where it was localized when it occurred alone at $0^{\circ}$. But when $\mathrm{P}_{3}$ was presented from the leftmost speaker $-20^{\circ}, 40^{\circ}$, or $60^{\circ}$ left-it was almost always (58 of 60 times) perceived as displaced to the right of where it was localized when sounding alone.

An analysis of variance was performed on perceived displacement scores for perceived position of $\mathrm{P}_{3}$ when at $0^{\circ}$. This analysis showed: (1) a significant effect of position of $\mathrm{P}_{4}\left(\right.$ at $20^{\circ}, 40^{\circ}$, or $60^{\circ}[\mathrm{F}(2,18)=4.32, \mathrm{p}<$ $.05]$; (2) a significant subject effect $[F(9,18)=31.47$, $\mathrm{p}<.01$ ]; and a significant interaction effect between these two variables $[F(18,18)=3.9, p<.01]$. No significant effect was found for position of $\mathrm{P}_{1}\left(10^{\circ}\right.$ right or $20^{\circ}$ right $)$. The significant effect of position $\mathrm{P}_{4}$ was due to large effects shown by three subjects. A rank-order test (Friedman) did not show a statistically significant effect of position of $\mathrm{P}_{4}$ on displacement-that is, the rank order for effects of position of $\mathrm{P}_{4}$ was not consistent across subjects. 
The average displacement to the left for $\mathrm{P}_{3}$ (presented from $0^{\circ}$ ) was $7.8^{\circ}, 9.4^{\circ}$, and $12.2^{\circ}$ when $\mathrm{P}_{4}$ was at $20^{\circ}, 40^{\circ}$, and $60^{\circ}$, respectively.

Another analysis of variance was performed on displacement scores for perceived position of $\mathrm{P}_{3}$ when $\mathrm{P}_{3}$ came from $20^{\circ}, 40^{\circ}$, or $60^{\circ}$ left (same position as $\mathrm{P}_{4}$ ). Displacement was measured from perceived location of a pulse from one of these speakers alone. Significant effects were found for (1) location of $P_{3}[F(2,18)=30.54$, $\mathrm{p}<.01]$, (2) subjects $[\mathrm{F}(9,18)=13.29, \mathrm{p}<.01]$, and (3) the interaction of these two variables $[F(18,18)=$ $2.72, \mathrm{p}<.05]$. No significant effect was found for position of $P_{1}\left(10^{\circ}\right.$ right or $20^{\circ}$ right $)$. The average displacement to the right for $\mathrm{P}_{3}$ presented from speakers at $20^{\circ}, 40^{\circ}$, and $60^{\circ}$ was $10.4^{\circ}, 17.0^{\circ}$, and $27.4^{\circ}$, respectively. The average localization of pulses coming alone from one of these speakers-at $20^{\circ}, 40^{\circ}$, and $60^{\circ}$-was $19.2^{\circ}, 36.3^{\circ}$, and $50.8^{\circ}$.

Further rank-order tests were run to test for the consistency of rank-order effects of position of $\mathrm{P}_{3}$ (in positions $20^{\circ}, 40^{\circ}$, and $60^{\circ}$ ). A rank-order test (Friedman) showed a significant effect of position of $\mathrm{P}_{3}$ on displacement, thus indicating a consistent rank-order trend across subjects $\left[\chi_{\mathrm{r}}^{2}(2)=18.53, \mathrm{p}<.001\right]$. A Friedman test on perceived angular location of $\mathrm{P}_{3}$ when it came from $20^{\circ}$, $40^{\circ}$, or $60^{\circ}$ left showed statistical significance $\left[\chi_{\mathrm{r}}^{2}(2)=\right.$ $12.9, \mathrm{p}<.01$ ], but a corresponding test on the perceived angular location of $\mathrm{P}_{3}$ when it came from $0^{\circ}$ did not show a significant effect of the location of the $\mathrm{P}_{4}$ at $20^{\circ}, 40^{\circ}$, or $60^{\circ}$.

\section{GENERAL DISCUSSION}

\section{Is the Last Pulse in the Sequence an "Attractant"?}

To explain the cutaneous "reduced rabbit," it has been proposed that $P_{3}$ in the sequence of three acts as an "attractant"; that is, $P_{2}$ is attracted, or displaced, toward the position of $P_{3}$ (Geldard, 1975). For our experiments, however, this hypothesis will not suffice, because the next to last pulse was displaced toward or away from the last pulse, depending on the physical position of the next to last pulse.

The leftward displacements we obtained in Experiment 2 were not as large as those reported by Sherrick (described in Geldard, 1975, p. 40). We repeated Sherrick's experiment on the "reduced auditory rabbit," using the method for localizing described for Experiments 1 and 2, and found displacements much smaller than those found by Sherrick. In this three-pulse experiment (run with 14 subjects), $P_{1}$ occurred at $20^{\circ}$ left, as did $\mathrm{P}_{2} ; \mathrm{P}_{3}$ occurred at $60^{\circ}$ left. Perceived displacements (to the left) found for $P_{2}$, with $P_{2}-P_{3}$ pulse separations of $100,200,300$, and $400 \mathrm{msec}$, were $6.8^{\circ}, 4.1^{\circ}, 2.6^{\circ}$, and $2.8^{\circ}$, respectively. A Friedman rank-order analysis of variance showed that the pulse separation time variable was significant $\left[\chi_{\mathrm{r}}^{2}(3)=9.92, \mathrm{p}<.02\right]$. Simple sign tests, however, showed that displacements were significant only for the 100 msec pulse separation $(\mathrm{p}<.01)$.

Instructions in all our experiments emphasized listening to the whole sequence of pulses from right to left. This instruction is especially im- portant in the case of the "reduced rabbit" experiment, in which $\mathrm{P}_{2}$ and $P_{3}$ occur as a pair, following $P_{1}$, which occurs $800 \mathrm{msec}$ earlier. We had earlier found (Thurlow et al., 1965) that some subjects could hear both members of a pair of successive pulses $\left(P_{A}, P_{B}\right)$ coming from the location of one of them (e.g., $P_{A}$ ) when the interpulse interval was less than about $100 \mathrm{msec}$, and the subjects were concentrating their attention at the location of that one $\left(\mathrm{P}_{\mathrm{A}}\right)$. $\mathrm{P}_{\mathrm{B}}$ could also be heard at its "real" location in space.

\section{Is Localization of All Pulses Shifted When Presented in a Sequence?}

We have measured displacements by taking the difference between localization of the next to last pulse in the series, sounded in sequence, and its localization when sounding alone. In an experiment designed similarly to Experiment 1 , and run with 10 subjects, we had the subject localize the positions of $P_{2}$ and $P_{4}$, both when these pulses were presented in the four-pulse sequence and when sounded alone. The average angular localization agreed closely (within $1^{\circ}$ ) for these pulses heard in sequence versus those heard alone.

Does the Subject Simply Perceive the Pulses Spread Out Spatially in Proportion to the Temporal Sequence?

If this were happening, then in Experiment 2 we would expect that the perceived location of $P_{3}$, presented at $0^{\circ}$, would shift substantially as the physical location of $\mathrm{P}_{4}$ was changed from $20^{\circ}$ left to $40^{\circ}$ and then to $60^{\circ}$ left-but it did not.

\section{Possible Special Expectation Mechanisms}

We know that there are powerful attentional-expectation effects on sound localization. The ventriloquism effect can be described in terms of an expectational facilitation acting on neural input spatial cues to the possible position of a sound source (Thurlow \& Jack, 1973). The ventriloquism effect occurs for speech stimuli when speech stimuli occur within $100 \mathrm{msec}$ of corresponding articulatory visual stimuli.

In the present experiments, we could suppose that a rapidly moving pulse sequence produces a rapid shift of attention, with an accompanying moving facilitation effect (related to previously established expectations about the relation between temporal and spatial position) that operates on neural cues to potential pulse location. In order to understand our results, however, we would have to posit separate neural mechanisms for shifting attention (by means of the changing location of pulses) and for perception of spatial location of these pulses.

\section{REFERENCES}

Blauert, J. (1983). Spatial hearing. Cambridge, MA: MIT Press. Bremer, C. D., Pittenger, J. B., Warren, R., \& Jenkins, J. J. (1977). An illusion of auditory saltation similar to the cutaneous "rabbit." American Journal of Psychology, 90, 645-655.

Geldard, F. A. (1975). Sensory saltation: Metastability in the perceptual world. Hillsdale, NJ: Erlbaum.

GelDARD, F. A., \& SHERricK, C., E. (1972). The cutaneous "rabbit": A perceptual illusion. Science, 178, 178-179.

ThuRLow, W. R., \& JACK, C. E. (1973). Certain determinants of the "ventriloquism effect." Perceptual and Motor skills, 36, 1171-1184.

Thurlow, W. R., Marten, A. E., \& BhatT, B. J. (1965). Localization after-effects with pulse-tone and pulse-pulse stimuli. Journal of the Acoustical Society of America, 37, 837-842.

(Manuscript received for publication June 27, 1984.) 